\title{
ARQUEOLOGIA E HISTÓRIA NA CONCEPÇÃO MODERNA DA CIDADE GREGA
}

\author{
Maria Beatriz Borba Florenzano ${ }^{1}$
}

Recebido em: 23/11/2021

Aprovado em: 27/12/2021

Resumo: Neste breve texto procuramos expor algumas de nossas reflexões sobre a relação entre a Arqueologia e a História como disciplinas do passado; reflexões construídas ao longo de minha carreira na Universidade de São Paulo.

Palavras-chave: cidade antiga; pólis; paradigmas interpretativos do passado; cidade e território; mobilidade no Mediterrâneo antigo

\section{ARQUEOLOGÍA E HISTORIA EN LA CONCEPCIÓN MODERNA DE LA CIUDAD GRIEGA}

Resumen: En este breve texto buscamos exponer algunas de nuestras reflexiones sobre la relación entre Arqueología e Historia como disciplinas del pasado; reflexiones construidas a lo largo de mi carrera en la Universidad de São Paulo.

Palabras clave: ciudad antigua; pólis; paradigmas interpretativos del pasado; ciudad y territorio; movilidad en el Mediterráneo antiguo.

\section{ARCHEOLOGY AND HISTORY IN THE MODERN CONCEPTION OF THE GREEK CITY}

Abstract: In this brief text, we seek to expose some of our reflections on the relationship between Archaeology and History as disciplines of the past; reflections built throughout my career at the University of São Paulo.

Keywords: ancient city; polis; interpretations of the past; city and territory; mobility in Ancient Mediterranean.

Antes de mais nada, quero agradecer o convite que muito me honrou de fazer a abertura deste ciclo de seminários. Espero que os que me ouvem não se decepcionem por eu apresentar um relato mais ou menos expressionista de minhas reflexões sobre as aproximações e

\footnotetext{
${ }^{1}$ Professora Titular de Arqueologia Clássica. Museu de Arqueologia e Etnologia da Universidade de São Paulo; cocoordenadora do LABECA/MAE/USP. E-mail: florenza@ usp.br Orcid: https://orcid.org/0000-0002-4350-2372
} 
distanciamentos entre Arqueologia e História na abordagem da cidade grega antiga. Digo expressionista porque, na verdade, este não é um tema fácil e implicaria em um aprofundamento muito grande para a elaboração de uma conclusão mais definida. No entanto, sendo este evento um Seminário, meu objetivo foi justamente o de abrir portas para a pesquisa de um tema historiográfico tão cativante e que me ocupou, na verdade, durante toda a minha carreira como arqueóloga e historiadora da antiguidade grega. Por isso também, quero acreditar que estas minhas reflexões possam abrir espaço para as indagações ou inquietações de quem se põe a refletir sobre Antiguidade. ${ }^{2}$

Assim sendo, o meu objetivo hoje é mostrar a vocês como dependeu em boa medida dos estudos de Arqueologia a ampliação do conhecimento a respeito da cidade grega antiga e consequentemente das formas de organização social, política, econômica do mundo helênico. A contribuição da pesquisa renovada sobre a materialidade do mundo helênico permitiu, em nosso entender, a superação de um paradigma interpretativo originário já desde a Renascença, mas sobretudo enraizado na Europa do final do século XVIII e do XIX que estabeleceu que o viés de análise da sociedade grega era a pólis como grupo de cidadãos; unidade basicamente institucional / política. Visão, por sinal, que persiste e muito entre os estudiosos da história da arte e da literatura, da arquitetura e do urbanismo, da ciência política, da filosofia e porque não explicitar, ainda entre muitos historiadores. Visão presente também em nossos manuais escolares e na escolha de obras a serem traduzidas para servirem como guias de História antiga em nosso meio acadêmico. Vem daí a minha teimosia em tratar ainda mais uma vez deste tema.

O relacionamento entre História e Arqueologia é, no fundo, uma temática que venho revisitando com insistência, à medida em que a minha reflexão sobre o métier do arqueólogo ‘clássico' foi se aprofundando. Em ao menos cinco publicações tratei desse enrosco que se apresenta ao estudioso do passado quando as fontes primárias são lacunosas e de categorias tão diversas e exigentes de metodologias específicas como o são as fontes materiais e as fontes escritas. Sobre a questão da contradição entre artefato e texto na análise de um tema específico publiquei um artigo da comunicação apresentada na reunião da Sociedade de Arqueologia Brasileira de 2001; sobre a relação entre Ciências Humanas e Arqueologia publiquei um artigo nas revista Anos 90 da UFRGS em 2003, sobre a origem da pólis vista pela Arqueologia publiquei um capítulo de livro em 2010 e mais recentemente tive a oportunidade de expor minhas reflexões sobre o relacionamento entre História e Arqueologia em duas entrevistas, uma para a Revista Heródoto da UNIFESP e outra para a Revista Romanitas da UFES. Entrevistas

\footnotetext{
${ }^{2}$ Neste artigo, o tom coloquial da conferência ministrada foi mantido. Algumas pequenas correções foram feitas visando sobretudo a maior clareza das ideias expostas.
} 
publicadas respectivamente em 2019 e 2020. (referências completas ao final do texto facilmente accessíveis em meu academia.edu) Hoje, pretendo mais uma vez chamar a atenção para a importância da Arqueologia para o estudo da antiguidade e especificamente para a redefinição do conceito de pólis em termos de historiografia.

Quando pensamos na fundação de um Laboratório para o estudo da cidade antiga, o Labeca, nosso objetivo era dar maior amplitude ao estudo da Arqueologia grega no MAE-USP. Tínhamos em mente ir além das especialidades de cada um: pensávamos buscar um contexto histórico maior onde essas mesmas especialidades de pesquisa pudessem ser articuladas de sorte a trazer uma maior contribuição para o estudo das formas de organização social da Grécia antiga. Àquele momento, em 2004, nos reunimos -professores e alunos- com regularidade para debater bibliografia teórica e metodológica que nos orientasse na criação de um projeto de pesquisa comum em torno de um tema suficientemente amplo que iluminasse os vários estudos já empreendidos e também aqueles que em 2004/2005 estavam em andamento.

Graças a uma colaboração com a Universidade Federal do Rio Grande do Sul, na figura do Prof. Francisco Marshall, como quem participamos de um projeto sobre a cidade de Apollonia em Israel, (a partir de 1998), escolhemos focalizar os estudos sobre a organização / disciplinamento do espaço sempre do ponto de vista da materialidade. Ora, conforme a construção historiográfica sobre a Grécia Antiga, a unidade de espaço básica, fundamental era a pólis, definida pela historiografia como "cidade-estado". Esse foi o nosso ponto de partida: nos propusemos a estudar a cidade-estado grega em sua materialidade.

Nos embrenhamos pelas leituras de obras importantes sobre a história da cidade grega antiga desde o século XIX; pelo debate de textos de história da arquitetura grega; na coleta de informações sobre cada cidade e seus aspectos urbanos. Dividimos nossas leituras e debates em três eixos principais: análise dos grandes intérpretes da história da Grécia em que, na maioria das vezes, a cidade -urbanisticamente falando- era sempre o ponto de partida e de chegada; história da arquitetura e do urbanismo em geral e especificamente da Grécia antiga; leituras de abordagens antropológicas do espaço e de sua organização. Na questão da história do urbanismo na Grécia antiga, focalizamos preferencialmente os especialistas arqueólogos e não necessariamente as generalidades sobre o desenvolvimento do urbanismo como faziam e fazem os arquitetos. $\mathrm{Na}$ verdade, as leituras na área de arquitetura foram fundamentais, sobretudo, quanto ao estabelecimento de teorias e metodologias para a análise do espaço. Amos Rapoport foi um apoio importante nesse sentido. Mas, na verdade, nos dedicamos bem mais aos trabalhos do arqueólogo francês Roland Martin e à História do Urbanismo escrita por Emanuele Greco e Mario Torelli, e de autores como Castagnoli e Ward-Perkins. Também procuramos subsídios 
nas abordagens antropológicas do espaço e por esse caminho nos inspiramos nas obras de Marcel Mauss e nas proposições da escola dos Annales. (todas as referências encontram-se listadas no site do Labeca e nos três projetos que animaram o Laboratório durante os últimos 15 anos)

Com efeito, o aprofundamento da pesquisa sobre a cidade antiga grega -nos 12 anos em que pudemos contar com o apoio da Fapesp- revelou os vários campos de estudo que estavam e ainda estão em aberto para uma melhor compreensão da interação entre espaço e sociedade na Grécia antiga. As obras a que tivemos acesso, sobretudo aquelas escritas a partir do final do século XVIII, evidenciaram para toda a equipe que a construção da História da Grécia valorizou sobremodo uma interpretação institucional da pólis. Percebemos como, inclusive, o uso do termo 'político' designando exclusivamente os assuntos dos governos é incongruente com o que os próprios gregos entendiam por pólis. Como já tive a oportunidade de mencionar outras vezes, a adoção do termo político nesse sentido, deve vir de Aristóteles quando este define o homem como um animal político, um zoon politikon. Parece-nos, no entanto, que Aristóteles valendo-se do adjetivo formado a partir de pólis, tenha se referido a uma pólis, cidade variada, diversificada, criativa, com homens, mulheres, crianças, estrangeiros e escravos distribuídos entre espaços organizados, adaptados, readaptados e em relação permanente com o 'outro' nas fronteiras. Relação esta que, por vezes, era conflituosa, mas que podia também ser pacífica. Pólis em que política, religião, economia não eram partes articuladas de um todo, mas aspectos sobrepostos e misturados deste todo. Esperamos que isto fique mais claro adiante.

Essa interpretação institucional das fontes textuais, fez com que a tradução de pólis passasse a ser "cidade-estado" e, como nos textos dos autores antigos dos séculos V e IV a.C. produzidos em Atenas, essa leitura sempre valorizou a independência e a autonomia da cidade. Assim, predominaram os estudos sobre as formas de organização institucional da pólis, do relacionamento entre póleis sobretudo por meio de guerras e de conflitos. Como nos explicam Etienne, Muller e Prost, em sua obra Archéologie Historique de la Grèce Antique, até os anos de 1990, a História da Grécia que se fazia era predominantemente (e ao menos na França) a História-batalha ou a História das instituições (2000, p. 19).

A Arqueologia da Grécia antiga, assim, no contexto do desenvolvimento das Ciências Humanas na academia europeia acompanhou este tipo de História, a História dos pequenos fatos, das ações militares, das instituições governamentais ao menos até a década de 1950 e mesmo até hoje em vários ambientes acadêmicos. E nessa posição, a Arqueologia não tem como ser uma disciplina independente. Ao contrário, mantem-se subalterna, como disciplina auxiliar da 'grande' História, escrita por historiadores a partir de uma leitura dos textos remanescentes. 
É como nos diz A. Snodgrass: “...a Arqueologia grega, de qualquer forma, esteve casada com, ou servindo ao tipo errado de História" (1987, p. 37). Em uma formulação bastante perspicaz, o mesmo autor explica que neste tipo de relação entre História e Arqueologia, vigia uma falácia positivista: “equalizava-se o que era observável com aquilo que era significativo" (idem, p. 40). Além disto, procurava-se ajustar a narrativa dos artefatos ao discurso desse tipo de História.

Ora pois, o documento arqueológico, material, dificilmente consegue responder às perguntas colocadas pelo texto escrito e por isso, em uma História desse tipo, este documento se reduz à ilustração da fonte escrita. Mas, em uma perspectiva arejada e renovada da Arqueologia clássica, mobiliza-se o documento material na elaboração de suas próprias perguntas e na valorização de uma metodologia própria que pode encaminhar investigações e fornecer ou encaminhar respostas.

Com relação especificamente à pólis, a Arqueologia da Grécia antiga, associada à uma História acentuadamente institucional aprofundou-se nos estudos monográficos sobre cada cidade grega. Procurava-se sobretudo desvelar as áreas urbanas que eventualmente são as mais densamente ocupadas. A procura por monumentos destacados na paisagem urbana como os espaços das decisões públicas, os espaços dos teatros, os grandes santuários, guiaram as escavações na Grécia durante o final do século XIX e toda a primeira metade do século XX. Naturalmente, nesse quadro, a cidade de Atenas, de onde provém uma grande quantidade de documentos escritos (talvez a maioria dos textos que nos foram legados da Antiguidade helênica), recebeu uma atenção ímpar. Desde o século XIX pesquisadores, amadores, literatos atentaram para os seus monumentos e para a respectiva disposição no espaço. Sobretudo a partir da década de 1930, com o aporte financeiro e científico de países europeus e dos Estados Unidos, grandes porções da cidade e da Ática em geral foram intensamente escavadas. A ágora, os edifícios públicos ali construídos, os grandes santuários foram aos poucos aparecendo e enriquecendo os Museus e alimentando as publicações. Mas as escolas arqueológicas fundadas na Grécia já desde o final do século XIX pelos países europeus e pelos Estados Unidos também se ocuparam de escavações monográficas de outras cidades, distribuídas em torno do Mar Egeu.

O caso da cidade de Olinto na Península Calcídica no norte do Mar Egeu é um modelo exemplar de escavação ligada à narrativa dos textos. É uma cidade muito mencionada pelas fontes textuais, sobretudo, as do século V e do século IV a.C. O fato de ter sido completamente destruída por Felipe II da Macedônia em 348, depois de um longo sítio, e não ter sido ocupada depois disto por outros assentamentos, tornou esta cidade bastante atrativa do ponto de vista da Arqueologia. O trabalho arqueológico neste sítio começou em 1928 e a temporada final de escavações foi em 1938, sempre coordenado por David Robinson da Universidade Johns 
Hopkins e sob os auspícios da American School for Classical Studies em Atenas. Conforme Lisa Nevett nos conta, a preocupação principal que guiou o projeto de escavação desta cidade e as primeiras temporadas do trabalho de campo foi a de encontrar edifícios públicos ou templos, objetivo repetido inúmeras vezes nos Relatórios de pesquisa feitos por Robinson. (Nevett, 1999, 53-54) Já a partir da segunda temporada de escavações, Robinson e seus colaboradores tiveram que - desapontados-- se render ao fato de que as escavações traziam à luz 'apenas' os elementos da organização espacial da cidade e sobretudo da arquitetura doméstica. Elementos àquela época analisados e utilizados como ilustração do que os textos antigos traziam a respeito das casas dos gregos.

É preciso reconhecer que também o Labeca tomou como ponto de partida nos seus primeiros quatro anos de funcionamento, a pesquisa por cidades, por pólis. Tanto que o nosso Banco de Dados reúne informações individualizadas por cidades. Da mesma forma, o resultado das pesquisas realizadas pelo Copenhagen Polis Centre, dirigido por Mogens Hansen e publicado em 2004, é um Inventário geral das pólis gregas. Listagem que reúne informações sobre mais de 1000 assentamentos reconhecidos pelos textos antigos como 'pólis'. Este grande projeto de pesquisa sobre a cidade grega arcaica e clássica é um excelente exemplo de como a abordagem da cidade grega antiga mudou radicalmente a partir dos dados do documento material. Iniciado como projeto de levantamento das fontes escritas a respeito de cada cidade, depois de dez anos de trabalhos, de reuniões, seminários, congressos, os verbetes sobre as cidades incorporam não apenas os dados da documentação textual como igualmente aqueles advindos das escavações e dos conhecimentos que apenas a Arqueologia pode fornecer como, por exemplo, a extensão territorial de uma pólis, as suas fronteiras. Cada verbete inclui, também bibliografia produzida pelas pesquisas arqueológicas e não raro são verbetes redigidos por arqueólogos. Ainda, entre os muitos capítulos da Introdução ao Inventário, há os que tratam da pólis como centros urbanos e há os que tratam da pólis como o conjunto do território, indicando uma abordagem muito mais complexa e rica do que a abordagem institucional que focaliza com prioridade as instituições e as formas de governo, a religião oficial e assim por diante.

Não é fácil, identificar as razões e os caminhos que as pesquisas sobre a antiguidade grega tomaram na construção dessas mudanças.

Como nos diz, com sabedoria, Emanuele Greco, em sua concepção crociana da História:

A escolha dos temas [e seu tratamento] segue, principalmente, os impulsos que procedem da história contemporânea e depois da capacidade dos pesquisadores, sejam eles os que leem as fontes e as inscrições, ou os que estudam as moedas ou aqueles que praticam a escavação ou a pesquisa no terreno, capacidade de comunicar, valorizar as descobertas e procurar a síntese possível. $(2006,63)$ 
Quais foram esses "impulsos da história contemporânea" que levaram a uma transformação da nossa compreensão da pólis grega? Não consigo enxergar um caminho único, mas faço aqui alguma tentativa.

Pensemos um pouco na situação da Europa depois da segunda Guerra Mundial, nas áreas em que a civilização grega havia se desenvolvido: a Grécia Balcânica, o sul da Itália, a Sicília. ${ }^{3}$ Um contexto histórico bastante específico em que reinavam a destruição, a pobreza, o desânimo. Tem início àquela época os vários projetos de reconstrução. Reconstruir o destruído que por força misturava-se -nessas áreas-- com o muito mais antigo. Na Itália, começa um trabalho de fotografação aérea, para identificar os danos e planejar o que fazer. Trabalho amplamente aproveitado pelos arqueólogos logo nas décadas de 1950 e 1960. A Arqueologia é de fato uma atividade caríssima se se propõe a realizar escavações em grande escala de cidades inteiras. As fotografias aéreas permitiram de uma forma muito mais econômica a detecção de amplas áreas de ocupação antiga, desvelando aos poucos a articulação entre centros urbanos antigos e seus respectivos territórios. Pode-se pensar que a partir dessa perspectiva amplificada começa-se a adotar de forma mais sistemática, em área de ocupação grega antiga, a técnica do levantamento espacial intensivo de material de superfície, os chamados Surveys.

Trabalhando com a longa duração - em uma inspiração direta da Escola dos Annales - a prospecção de superfície propõe uma abordagem regional e não local. Ao estudar amplas extensões de território, a prospecção intensiva acaba identificando no tempo as alterações dos padrões de uso agrícola da terra, as separações entre território sagrado e território dessacralizado, a organização do trabalho e da produção, o regime de propriedade, a organização dos assentamentos na terra e assim por diante. Na medida em que trabalha apenas com fragmentos de artefatos e de estruturas e com a intensidade de sua distribuição no espaço foge da descrição minuciosa e monográfica típica da Arqueologia tradicional, ao mesmo tempo em que traz uma contribuição verdadeira com relação ao funcionamento das sociedades. (Florenzano, 2003, 18-19)

A prospecção sistemática de superfície - o survey - permitiu ainda, no caso da Grécia Antiga, identificar as áreas de sinecismos de época arcaica (junção de pequenos assentamentos na configuração inicial da pólis que é registrada em algumas fontes escritas) e permitiu igualmente compreender os mecanismos que entraram em ação na configuração da Grécia antiga prioritariamente em unidades poleicas, diferentemente da explicação geográfica

\footnotetext{
${ }^{3}$ Não incluo o Mar Negro por ser uma área que foi pouco estudada no Labeca ainda que intensamente ocupada pelos gregos desde o século VIII-VII a.C. A maior parte da bibliografia a respeito das escavações nesta região é em russo ou em outros dialetos regionais que dificultam o nosso acesso aos dados. Apenas a partir da década de 1990 é que alguma coisa foi traduzida e ainda nos anos 2000 alguns periódicos específicos têm sido editados em inglês.
} 
tradicional como a proposta por Finley em que o isolamento dos assentamentos em pequenas cidades era o resultado do terreno montanhoso e da consequente dificuldade de comunicação (1963). No tipo de investigação promovida pelos surveys, a pólis, como uma entidade institucional, como um centro urbano que tem o poder de controlar um território -território que está presente em muitos textos antigos-, mas que foi pouco notado pela leitura dos historiadores da "História institucional", a pólis como 'cidade-estado', fica diluída no quadro do funcionamento da sociedade grega em toda a sua complexidade e na sua articulação com outras pólis e com as populações não gregas presentes em muitas de suas fronteiras. Essa pólis institucional sai do foco e abre espaço para a pesquisa sobre o funcionamento da sociedade como um todo.

O relacionamento entre as diferentes póleis e entre póleis e as populações não gregas no Mediterrâneo é um aspecto fundamental da cidade antiga grega que a Arqueologia consegue colocar a nu por meio do estudo do espaço. Além disto, é a partir desse estudo que novos nuances sobre a construção de uma identidade helênica que brota desses relacionamentos mantidos na hinterlândia e nas fronteiras das cidades. E aqui me deterei um pouco mais em vista que boa parte dos trabalhos desenvolvidos no Labeca exploraram essa questão.

Com efeito, nos anos que vimos trabalhando no Labeca, a valorização do documento arqueológico permitiu-nos perceber o seu potencial no processo de caracterização da cidade grega antiga em que, além dos elementos especificamente institucionais, os traços de uma sociedade complexa, heterogênea aparecem inscritos no terreno. $\mathrm{O}$ estudo sistemático da distribuição dos vestígios arqueológicos na configuração da hinterlândia grega, por exemplo, permitiu-nos ultrapassar uma definição restrita de pólis centralizada no núcleo urbano com seus edifícios governamentais e religiosos e no seu território imediato.

O aprofundamento de nossos estudos sobre a hinterlândia grega -sobretudo nas áreas periféricas do mundo helênico a Ocidente e a Oriente- permitiu-nos desenhar e comprovar a hipótese de que não apenas a khóra -o território das cidades-- era estruturante da sociedade como serviu de cadinho para relações culturais múltiplas que trouxeram uma contribuição indispensável à configuração da própria identidade grega, do que hoje conhecemos pelo nome de helenismo ou helenidade. A khóra é parte engastada no núcleo urbano que dela depende não apenas para a produção agrícola, mas dela depende ideologicamente.

Nesse sentido, entendemos que o "modo de ser grego" irradiado a partir da Grécia balcânica e egeia, incluía a necessidade fundante da posse de territórios, independentemente das necessidades básicas de sobrevivência, e incluía também uma competitividade entre os próprios gregos pelo domínio de territórios; traço não identificado, por exemplo, entre as 
populações indígenas ${ }^{4}$ da Península Itálica ou da Sicília. Estas funcionavam com concepções diferentes de espaço. (Florenzano, 2018) Pensamos que justamente este "modo de ser grego" levou a partir do séc. VIII a.C. a um movimento de expansão pelo Mediterrâneo que promoveu uma série de instalações de assentamentos litorâneos que imediatamente passaram a procurar um maior domínio territorial, em direção às respectivas hinterlândias. Nessa busca, entraram em contato tanto com as populações não gregas instaladas previamente nestas localidades quanto com outros gregos igualmente assentados e igualmente procurando novas bases territoriais. Entre conflitos e negociações, essas sociedades vão se organizando e dando forma a um mundo novo. (Florenzano, 2009; 2018; 2019a) Esta movimentação de gregos, neste período no Mediterrâneo faz parte dos processos de criação e consolidação da estrutura organizacional representada pela pólis. Processos que incluíram tanto o assim chamado Ocidente grego quanto a Grécia Balcânica e a região do Egeu. Também aqui, o compartilhamento de traços culturais teve uma grande importância na formação da própria helenidade. (Morris, 1998) Ressalte-se igualmente a relevância da continuidade de contatos entre os helenos da parte oriental do Mediterrâneo e suas respectivas fundações a Ocidente, criando-se um imbricamento múltiplo entre tradições, costumes, formas organizacionais da sociedade, formas políticas e assim por diante. A ocupação de territórios e a definição de fronteiras constituem elemento fundamental neste processo. A pólis aparece assim -por meio da Arqueologia- inserida em um contexto mediterrânico muito mais amplo em que unidade e diversidade trabalham juntas alternando-se em intensidade conforme o local e o período, como gosta de marcar sempre o Prof. Norberto Guarinello.

E é este grande contexto mediterrânico em que se inserem as muitas redes de contato que ultrapassam os limites estritos da cidade urbanizada e que nos permite compreender muito melhor a natureza e a própria configuração da sociedade grega. Nesse sentido é que podemos visualizar/compreender/ o papel predominante das redes (networks) na estruturação das cidades gregas antigas. E nisto, a Arqueologia pode andar de mãos dadas com a História, na identificação do funcionamento destas redes de transferência de artefatos, mas também de ideias e de conhecimentos, de conceitos e, enfim, de visões de mundo; organização dos gregos, em articulação permanente com os não gregos em muitos níveis e esferas diferentes, como nos

\footnotetext{
${ }^{4}$ É sempre necessário explicar que as populações não gregas de áreas que entraram em contato com os gregos no Mediterrâneo são chamadas há décadas, impropriamente, pela bibliografia especializada de indígenas. Não entramos aqui em detalhes sobre os caminhos da adoção desta terminologia, mas, no diálogo com a produção científica especializada, não há como não a empregar. Mesmo assim, tentamos usar a expressão "não gregos", na medida do possível.
} 
ensina Irad Malkin em sua obra A Small Greek World de 2011, ideias retomadas em muitos outros textos mais recentes.

O tema da mobilidade é um dos temas em que a Arqueologia se movimenta com agilidade/ na medida em que a variedade e a mistura de traços de origens diferentes presentes no documento material podem transformar-se em indicadores preciosos do relacionamento entre grupos humanos diversificados. Por outro lado, a dispersão e a circulação de artefatos de origens conhecidas por grandes regiões - e aqui pensamos no Mediterrâneo antigo - também oferecem indicadores valiosos na identificação de áreas de influência e de absorção de traços culturais estruturantes de uma sociedade. Lembre-se que dispersão e circulação de artefatos foi e continua sendo objeto dos trabalhos arqueológicos desde a própria criação da disciplina no final do século XIX.

Como se sabe, e é bem documentado arqueologicamente, a mobilidade de grupos humanos no Mediterrâneo é bem anterior aos anos 700 a.C., entretanto, é neste século VIII a.C. que grupos de gregos, de origens diversificadas, provenientes do Egeu, da Grécia oriental ou dos Bálcãs, começaram a fundar instalações permanentes sobretudo ao sul da Península Itálica e na Sicília em um processo que desemboca na configuração da pólis. (Como já disse, conheço bem menos os processos de colonização no Mar Negro e não me aventuro aqui a tratar desse assunto) Este processo de expansão, provocou uma série de transformações sociais, culturais, políticas, econômicas que tiveram reflexos em todo o ambiente mediterrânico. $\mathrm{O}$ contato entre grupos diferentes provocado por esta mobilidade foi, sem dúvida, apropriado pelos gregos como um elemento criativo e próprio do dinamismo helênico inerente à própria estrutura da cidade antiga grega, da pólis.

Já caminhando para a conclusão desta palestra, voltemos aos "impulsos da história contemporânea", que nas palavras do Professor Emanuele Greco conduzem às escolhas de temas de pesquisa.

Comecemos por chamar a atenção para a questão do avanço tecnológico dos últimos vinte anos (hoje uma banalidade) que nos coloca em contato com o outro lado do mundo em segundos. A guisa de exemplo, lembro aqui os muitos estudos sobre as transformações sociais provocadas pela rapidez da comunicação com a construção das ferrovias iniciada no século XIX. Hoje, a rapidez da comunicação, o acesso a culturas, costumes, hábitos diferentes dos nossos se realiza em uma velocidade incomparável, colocando-nos diante da possibilidade de reflexão sobre as vantagens e desvantagens de seguir um modelo de sociedade ou outro, de governo, de moda, de alimentação, de crença e de tudo que nos circunda. Esses fatores já vêm orientando a reflexão historiográfica há algumas décadas e não há ingenuidade em concluir que 
são eles que, em grande medida, nos levam a tentar compreender os critérios e os efeitos do relacionamento entre grupos humanos no passado.

Focalizar as migrações e as diásporas de populações, e analisar o papel das redes na construção de identidades e nos processos de transformação das sociedades não significa que estejamos mobilizando um velho paradigma interpretativo de acordo com o qual as sociedades se transformavam à medida que incorporavam traços exteriores. Em uma postura mais eclética, não podemos ignorar a relevância da difusão em associação aos processos internos de transformação. Na verdade, as coisas são bem mais complexas do que o nosso racionalismo poderia supor. Mas, tenho certeza de que a contribuição da Arqueologia nessa área é capital.

Não é o lugar aqui para explorar em profundidade os paradigmas que informam hoje em dia nossa atitude em relação ao passado. Não conseguiria explicitar tantos caminhos percorridos pelas Ciências Humanas na busca de uma melhor compreensão daquilo que veio antes de nós: concepções criadas pela Escola dos Annales, retomadas uma e outra vez, a Nova História, a New Archaeology; o modernismo, o pós-modernismo, o processualismo, o pós-processualismo, as muitas mudanças de paradigma interpretativo que veem mexendo profundamente com a maneira como buscamos o passado. Outros o fizeram com maior competência e profundidade do que eu poderia realizar no curto espaço desta palestra. Cito como exemplo as reflexões de Carandini em entrevista de 2012 (Il nuovo dell'Italia è nel passato) de Morris, sobre o assunto em seu texto de 1994 (Archeologies of Greece) ou naquele de 2005 (Mediterraneanization) que conseguem mostrar alguns caminhos dessa mudança entre as idas e vindas do caminhar das Ciências Humanas na Europa entre o Renascimento e o século XX.

No âmbito justamente das Ciências Humanas, como se associam hoje Arqueologia e História? Sem dúvida alguma, a Arqueologia deixou de ser aquela 'ciência auxiliar' de uma ciência 'mãe'; deixou para traz esse papel subalterno em relação à História e em pé de igualdade e independência disciplinar vem propondo temáticas e metodologias específicas para o tratamento da Antiguidade. E repito aqui as palavras de Emanuele Greco para quem o diálogo entre a Arqueologia e a História é sempre vivo e depende

da capacidade dos pesquisadores, sejam eles os que leem as fontes e as inscrições, ou os que estudam as moedas ou aqueles que praticam a escavação ou a pesquisa no terreno, capacidade de comunicar, valorizar as descobertas e procurar a síntese possível. $(2006,63)$

Acredito, pois, pelo que acabo de expor a vocês, e eu espero tê-los convencido, que a contribuição da Arqueologia foi decisiva para a renovação dos estudos sobre a cidade grega antiga. Em outros tempos, os estudos sobre a Grécia antiga estavam focalizados de forma 
enviesada em uma História da pólis institucional, sobretudo das formas de governo; hoje, sem ignorar a história das instituições, graças à Arqueologia, podemos conceber uma pólis mais multifacetada, independente, mas partícipe de redes de relacionamento importantes com outras pólis e com populações não gregas no Mediterrâneo. Relacionamento, de fato estruturante, da sociedade grega antiga.

E assim, parece-me que saímos de uma História da Grécia resumida à História das "cidades-estado" para uma História grega no Mediterrâneo como bem expressa o título da pesquisa de pós-doutoramento de Guilherme Moerbeck, desenvolvida no âmbito do Labeca MAE/USP.

\section{Referências bibliográficas}

CARANDINI, Andrea. Il nuovo dell'Italia è nel passato. Intervista a cura di Paolo Conti. Bari: Laterza, 2012.

CASTAGNOLI, Ferdinando. Orthogonal Town Planning in Antiquity. Cambridge: MIT Press, 1971.

ÉTIENNE, Roland; MÜLlER, Christel; PROST, Francis. Archéologie Historique de la Grèce Antique. Paris: Ellipses, 2000.

FINLEY, Moses Israel. The Ancient Greeks. Harmonsworth: Penguin, 1966 [1963]

FLORENZANO, Maria Beatriz Borba. Entre o artefato e o texto: a moeda no mundo antigo. Em: XI Congresso da Sociedade de Arqueologia Brasileira: A Arqueologia no novo milênio. Rio de Janeiro: SAB, 2001, p. 61-73.

FLORENZANO, Maria Beatriz Borba. Arqueologia Clássica e Ciências Humanas. ANOS 90, v. 10, n. julho 2002, p. 13-22, 2003.

FLORENZANO, Maria Beatriz Borba. A contribuição das colônias ocidentais na construção da identidade políade: subsídios do uso e organização do espaço. Resultados preliminares. In: FLORENZANO, Maria Beatriz Borba (Org.), Estudos sobre a cidade antiga. São Paulo: EDUSP, 2009, p. 1-18.

FLORENZANO, Maria Beatriz Borba. A origem da pólis: os caminhos da Arqueologia. In: CORNELLI, Gabiele (Org.) As representações da cidade antiga: categorias históricas e discursos filosóficos. Coimbra: Clássica Digitalia, 2010, p. 39-49.

FLORENZANO, Maria Beatriz Borba. A organização da khóra na Sicília grega sul-oriental: Siracusa diante de sua hinterlândia (733-598 a.C.). Cadernos do Lepaarq (UFPEL), v. 15, p. 246, 2018.

FLORENZANO, Maria Beatriz Borba. Definindo a pólis: o papel das fronteiras na integração do espaço políade. In: FLORENZANO, Maria Beatriz Borba (Org.) Khoríon. Cidade e Território na Grécia Antiga. São Paulo: Intermeios/Fapesp, 2019a, p. 147-161.

FLORENZANO, Maria Beatriz Borba. Cidades e Periferias no Mundo Antigo. Entrevista concedida a Gilberto Francisco. Heródoto: Revista do Grupo de Estudos e Pesquisas sobre a Antiguidade Clássica e suas Conexões Afro-asiáticas, v. 4, 2019b, p. 5-25.

FLORENZANO, Maria Beatriz Borba. As póleis do Ocidente grego à luz da Arqueologia Clássica: uma entrevista com Maria Beatriz Borba Florenzano. Romanitas - Revista de Estudos Greco-latinos, v. 15, 2020, p. 9-19. 
GRECO, Emanuele; TORELLI, Mario. Storia dell'Urbanistica. Il mondo greco. Bari: Laterza, 1983.

GRECO, Emanuele. Dialogo tra storici ed Archeologici: spunti per uma discussione. In: Passato e futuro dei Convegni di Taranto. Atti del $\mathbf{4 6}^{\circ}$. Convegno di Studi sulla Magna Grecia-2006. Taranto: 2007, p. 61-77.

HANSEN, Mogens Herman; HEINE NIELSEN, Thomas. An Inventory of Archaic and Classical Poleis. Oxford: Oxford University Press, 2004.

MALKIN, Irad. A Small Greek World. Oxford: Oxford University Press, 2011.

MAUSS, Marcel. Sociologia e Antropologia. São Paulo: Edusp, 1974.

MORRIS, Ian. Classical Greece. Ancient Histories and Modern Archaeologies. Cambridge: Cambridge University Press, 1994.

MORRIS, Ian. Archaeology and Archaic Greek History. In: FISCHER, Nick; VAN WEES, Hans (Org.). Archaic Greece: New Approaches and New Evidence. Londres: Duckworth Press, 1998, p. 1-91.

MORRIS, Ian. Mediterraneanization. In: MALKIN, Irad (Org.). Mediterranean Paradigms and Classical Antiquity. Londres: Routledge, 2005, p. 30-55.

NEVETT, Lisa C. The city of Olynthos: a detailed case-study in domestic organisation. In: House and society in the ancient Greek World. Cambridge: Cambridge University Press, 1999, p. 53-79. Tradução disponível em: http://labeca.mae.usp.br/pt-br/articles/translations/

SNODGRASS, Anthony. An Archaeology of Greece. The Present State and Future Scope of a Discipline. Berkeley: University of California Press, 1987.

SNODGRASS, Anthony. Archaeology and the Emergence of Greece. Ithaca: Cornell University Press, 2006.

WARD PERKINS, John Bryan. Cities of Ancient Greece and Italy: Planning in Classical Antiquity. London: Sidgwick \& Jackson, 1974. 